Please, cite as follows:

Parra-Meroño, María C.; De-Juan-Vigaray, María D.; Volcan, Lilian E. (2020) The gender gap in intellectual property in Latin America and Iberia: the case of patents, International Journal of Intellectual Property Management, Vol.10 No. 4 pp. 345 - 374 DOI: 10.1504/IJIPM.2020.112417

\title{
The gender gap in intellectual property in Latin America and Iberia: the case of patents
}

\author{
María C. Parra-Meroño \\ Social Sciences, Law and \\ Business Administration Department, \\ Catholic University of Murcia, \\ Campus de los Jerónimos, \\ E-30107 Guadalupe Murcia, Spain \\ Email: mcparra@ucam.edu
}

\section{María D. De-Juan-Vigaray*}

Marketing Department,

Faculty of Economic and Business Sciences,

University of Alicante,

Campus de San Vicente del Raspeig,

E-03080 Alicante, Spain

Email:mayo@ua.es

*Corresponding author

\section{Lilian E. Volcan}

University of Oxford International Gender Study Centre,

7 Mary Price Close, OX3 0LN, Oxford, UK

Email: volcanle@hotmail.com

\begin{abstract}
The World Intellectual Property Organization (WIPO) indicates two important gender gaps in the field of Intellectual Property (IP): 1) the difference between men and women in IP registry figures; 2) the significant concentration of IP registries in less than 20 countries. This study analyses the status of IP registered by women in the countries of Latin America (LATAM) and Iberia (IBER, Spain and Portugal) in comparison to the rest of the world. Given that there is scarce literature on IP sourcing from a gender perspective, a qualitative and quantitative analysis is offered in this research as an attempt to close this gap. The qualitative analysis is based on a comprehensive desk research on various documentary sources, while the quantitative research is based on official data from the World Intellectual Property Organization (WIPO) of the United Nations (UN). Findings indicate that women bring instrumental contribution to IP in Latin America and Iberia. However, since their achievements still remain unnoticeable, relevant policies and incentives will be necessary to close this gap.
\end{abstract}

Keywords: gender; Latin America; Iberia; patents; patent cooperation treaty; PCT; intellectual property.

Reference to this paper should be made as follows: Parra-Meroño, M.C., De-Juan-Vigaray, M.D. and Volcan, L.E. (xxxx) 'The gender gap in intellectual property in Latin America and Iberia: the case of patents', Int. J. Intellectual Property Management, Vol. X, No. Y, pp.xxx-xxx. 
Biographical notes: María C. Parra-Meroño holds a $\mathrm{PhD}$ in Business Administration and Management, Organization and Marketing from the Catholic University of Murcia (UCAM, Spain), and a Bachelors degree in Economics and Business Administration from the University of Murcia. She is a Lecturer and Head of the research group Marketing, Business Administration, and Economics at UCAM. Her teaching and research interests deal with consumer behaviour and marketing, communication, tourism and international relations. She is an author of six books and 40 scientific articles, in journals such as Personal and Ubiquitous Computing, Innovative Mobile and Internet Services in Ubiquitous Computing, Journal of Knowledge Management, International Journal of Scientific Management and Tourism or Social Sciences, Sensors, Sustainability. She has participated in several research projects.

María D. De-Juan-Vigaray has a PhD in Marketing and is an Associate Professor at the Faculty of Economics at the University of Alicante (Spain), and a Visiting Professor at IESEG School of Management in France. She has been a Lecturer at the University of Florida (USA), Southampton Business School (UK), and Spanish business schools (e.g. ESIC (Madrid), ESADE (Barcelona). She is an author of several books on marketing, as well as articles on intercultural behaviour on the net and commercial distribution, publishing in journals such as the Journal of Tourism Management, Journal of the Academy of Marketing Science and Journal of Consumer Psychology. Her research focuses on cross-cultural issues, children, gender, and educational innovation.

Lilian E. Volcan holds a $\mathrm{PhD}$ in Agricultural Economics and Policies (University of Bologna, Italy). She is a Research Associate at the University of Oxford International Gender Study Centre at Lady Margaret Hall (IGS-LMH). Her research and teaching focuses on knowledge transfer and the appropriation of information and communication technologies (ICTs) to catalyse social change, specifically in communities facing social, political, and economic challenges. She is the author of 'A gender perspective on the technology transfer and wealth creation' (2019). For over a decade, she has worked in progressively senior roles in multilateral organisations with a focus on SMEs competitiveness to build inclusive and wealthy communities in the global south.

\section{Introduction}

If it were not for publications by women such as Simone de Beauvoir (1949) on gender equality -Le Deuxième Sexe-, highlighting the achievements of the 'feminist movement' in the 1930s, [e.g., voting rights, (Lagarde, 1996)], the importance of gender equality and the lack of it at all levels in our society, we would not be able to document this analysis or even talk about this matter at all. Looking at the literature that emerged later on, we found that an investigation carried out by the Division for Cultural Development of UNESCO in 1981 Cultural Women and Industries (Mattelart and Reader, 1982) identifies a noteworthy account signposting that the mass media reflected women's oppression in society due to their 'invisible work' (unpaid housework) and 'reproductive role' (transmitting values such as morals, affection and education).

In the following decades, it seems that such oppression was reducing to concede power to women in decision-making when purchasing products. Nowadays, in a modern 
household the decisions on what to buy and what to save are taken by both the male and female in more equal proportion. For instance, in countries such as the USA and Spain, women make $80 \%$ of the decisions on purchases (Castillejo, 2011). On a point of IP, though, the literature seems to indicate that the participation of women in IP creation and registration has been rather ubiquitously unnoticeable and sluggish.

According to Khan (2000) during the nineteenth century, for example, if women created certain inventions it was treated as a taboo subject and therefore no social or legal recognition for their work was made public but, curiously, done anonymously or under a pseudonym (e.g., Clara Schumann, the wife of famous German composer Robert Schumann). At that time, it was socially inappropriate for a woman to get a patent and unthinkable for her to register her IP. Because of this, many women's patents were obtained in the name of a male relative. Has this situation changed in recent decades? For most, although much technological progress has been achieved on many fronts with the proactive participation of female scientists, the functions of the formal sphere from which IP generally arises have been totally closed to women (Burk, 2018). In fact, Lefeuvre et al. (2018, p.1) cogently argue that "women contribute to all areas of creativity and intellectual work, but their achievements often remain hidden".

In the 21 st century, the tendency is to downplay explicit hurdles for female inventors and creators at institutional level. However, statistical trends still remind us that gender bias continues to exist even in modern countries. For example, today only $4 \%$ of patent applications in Germany include a female inventor and, in the USA only 10\% (Hoisl and Mariani, 2017). The gender gap is also pronounced in science and technology (e.g., innovation), see Bell et al. (2019) in the Americas, and Paul and Mukhopadhyay (2010) in India. Trademarks in the European Union are also a good example (Roberge and Durning, 2019) as well as in the case of Finland (Heikkilä, 2019). This is also observed by Burk (2018) who says that in no way does the number of patent applications filed by women bring us even remotely closer to gender parity. As pointed out in the literature (Mauleón and Bordons, 2006; Frietsch et al., 2009; Naldi and Parenti, 2002) there is an urgent need to clarify data on gender.

It is within this framework that this paper tries to fill this gap by analysing the issue of female participation in IP creation and registration in LATAM and Iberia (hereinafter referred to as IBER), and its potential for gender equality. We hypothesise that women's participation in the IP creation and registration process in LATAM and IBER is affected by both external or internal segregation factors (social or structural) and posit that, if this gap is addressed with inclusive IP policies, an increased trend in women's profiles in IP protection in these regions can be achieved in the medium to long term at a higher equality rate compared with other regions in the world. The article studies a relevant research problem with applied impact. It proposes policy measures that could contribute to reducing gender gaps and increasing patents. It is relevant for scientific literature to improve research and development in this field. After examining the current patenting situation in LATAM and IBER, we discuss how patriarchy mediates the relationship between IP and gender. We then investigate possible impacts, by first reviewing the potential for IP to reduce gender inequalities, and then addressing the ways in which it might exacerbate such inequalities. Finally, we make relevant conclusions with policy recommendations to address the challenges to IP as a key for development and poverty alleviation in the studied area. 


\section{Literature background}

Collective thinking, which contemplates aspects such as art, culture or traditions, gives different parameters, roles and values to each gender, and behaviours of both and can be assessed as appropriate or inadequate depending on who performs them. According to Monreal-Gimeno and Martínez-Ferrer (2010) different values can be linked with the masculine and feminine stereotypes: e.g., the masculine one is linked to 'being active' while the feminine is linked to 'dedication to others, being emotional'. In terms of roles, the masculine one is synonymous with 'economic control' whereas the feminine relates to 'kitchen'. Physical characteristics are assigned: 'corpulent' to masculine and 'gracious' to feminine, while, for cognitive skills: 'abstract thinking' for the masculine stereotype and 'intuition' for the feminine one.

The gender concept is the key to understanding the differentiated places that women and men occupy in society and, therefore, in the knowledge generated. It considers the way in which relations between the sexes are produced and institutionalised (Moreno, 2000). These are non-equal relationships between genders, since they are established by internalising a differentiated socialisation. The issue of gender is on the table. The concept of gender allows us to begin to deconstruct inequality, and with that to transform the world into a more egalitarian place (Reverter, 2012). This term refers to social constructions that vary over time, space and cultures. Regarding gender perspective, we took the indications of Pacheco (2004) who states that it is a theoretical framework that allows us:

a to give visibility to the position of women with respect to men, distinguishing the differences between both physical and sexual

b to locate the factors that contribute to inequality

c to design actions to change those factors that perpetuate inequity.

In this study, after identifying the factors that contribute to IP inequality, we will be able to highlight two non-exclusive strategies for the incorporation of gender in IP. One would be those specific policies designed to address particular problems and/or specific groups; and the second strategy would be what we know as gender mainstreaming, where inequality between women and men is addressed from a holistic approach (e.g., HERA, Mainstreaming of Gender in Public Administrations, Instituto de la Mujer, 2007). In public equality policies, mainstreaming was defined by the European Council Expert's Group as: "the organization (reorganization), improvement, development and evaluation of political processes, so that a perspective of gender equality is incorporated into all policies, at all levels and at all stages, by actors normally involved in the adoption of political measures" [Council of Europe, (1998), p.26].

Moreover, the European Council recommends reviewing the aspects of education systems so that they promote gender equality. Specifically, in Spain, the Law of Equality, and the Organic Law of Universities 6/2001 (LOU) contain indications related to the promotion of education and research on the meaning and scope of equality between men and women and the carrying out of studies and specialised research.

Equal education opportunities for men and women are an essential requirement to reduce gender inequalities of our society. According to Casella and Coelho (1995, p.8): "It is necessary, therefore, to introduce gender perspective in the process of project development, as a way to ensure new insertions of women in society based on equity". 
Despite this, the data indicates that, although there are more women who graduate and also gain Master's degrees, interestingly, there are far fewer women who finish their $\mathrm{PhD}$ program and still fewer less of those who work as researchers. We are facing the phenomenon of the 'leaky pipeline' [Huyer, (2015), p.3]. It is possible to think that the aforementioned stereotypes do not happen already in business areas; far from reality. It is true that there are many companies that have equal gender egalitarian staff and that also care for of their employees in the field of corporate social responsibility (CSR) to promote and ensure equality between men and women.

However, one of the fields of study is the discrimination factors against women in companies and the difficulties they face in reaching managerial positions (Kaufmann, 1999; Writh, 2002). Two groups of factors influence these inequalities, external and internal. The external refers to the environment in which the company operates, while the internal encompasses work procedures, organisational culture and the way people interact. According to Dema (2007) these factors cause two types of segregation: horizontal (e.g. 'men's jobs' and 'women's jobs'; in Europe, companies in the cleaning sector usually have predominantly female staff, while in the US they are male) and vertical (the 'glass ceiling' that refers to the small number of women who reach senior positions in organisations). Thus, women who work in companies and corporations with hierarchical organisational structures tend to participate less in activities related to intellectual patents than men (Lax Martínez et al., 2016). Studies also support the idea that, when inventing, women tend to be part of larger research groups that men [Naldi et al., 2004; Busolt et al., 2008; European Studies on Gender Aspects of Inventions-Statistical Survey and Analysis of Gender Impact on Inventions (ESGI); Moody, 2004]. Another noteworthy aspect is wage discrimination, in which women receive less remuneration for doing the same work than men (D'Alessandro, 2018).

Since IP as a management discipline offers tremendous opportunities for social and economic change and, as the strategic use of IP becomes more widespread among the growing number of IPR-intensive industries, there has been an associated increase in attempts to understand the social, economic and political implications of IP sourcing for these industries. One significant gap in this work, however, is a critical analysis of IP sourcing in terms of gender. This research also aims to address this gap by examining the gender implications of IP sourcing at the early stages of the innovation process with an emphasis on women's participation in the filing of patents.

\section{Methodology}

The research framework predominantly involves desk research as a tool to answer the conceptual and empirical questions of this research. Desk research is an exceptional tool for putting together pieces from different fields (e.g., showing the market, the IP, gender studies) and the trends (Cooke et al., 2002; Hague et al., 2004). It is related to published reports and statistics as well as other types of information such as "the Internet or speaking to someone at a trade association or carrying out interviews with experts" (Hague et al., 2004).

At the conceptual level, the qualitative part, we looked at factors affecting women's involvement in the IP sourcing process. The assumption here was that if these factors are recurrent throughout the IP creation and protection process, their impact may be cumulative and incremental with ensuing erosion of women's interest in IP related fields 
and jobs. At the empirical level, the quantitative, we considered several data sources and making use of this valuable database, allowed us to respond to the questions:

1 What is the level of women's involvement in patent filing in LATAM and IBER?

2 What are the trends indicating?

\subsection{Qualitative analysis}

Literature from different gender and IP sources were reviewed during the months of April to June 2019. Also, valuable and reliable sources of data on institutions' secondary information were identified. More precisely, information was collected from the following sources:

\subsubsection{Reviewing electronic databases and library resources}

We conducted a systematic search of electronic databases to identify key academic, reliable and prestigious published research papers on IP and gender. Among the electronic databases that were reviewed are: Web of Science, ISI Social Science Citation Index, Book reviews, Emerald, ISI Social Science Citation Index, SJR Scimago Journal \& Country Rank, Conference papers, books, working papers and dissertations. The aforementioned databases were systematically searched using the following search key words: gender, women discrimination, IP, women and IP, gender and IP.

Our review noticed an important gap in the geographical areas of LATAM and IBER. The following was introduced into the search "Latin America IPR SME HelpDESK First Line IP Assistance Service for European/COSME Small and Medium Enterprises (EU SMEs and SMEs from the Associated Countries)" that operates or intend to access the Latin American market towards improving their global competitiveness.

\subsection{Quantitative analysis}

Data was recorded to evaluate accuracy and cross-checked by two or three sources to detect anomalies. Valuable and reliable sources of data on institutions' secondary information and therefore fruitful for profiling IP activity and actors in the market, were used by analysing data from 2000 to 2018 . Several IP sources of disaggregated data by gender were also reviewed between April and June 2019. Due to the fact that the World Intellectual Property Organization (WIPO) PCT and individual LATAM + IBER countries was published online for the first time in May 2019, this database is the most contemporary, resourceful and unique source of information for this specific topic. More precisely, information was collected from the following sources:

\subsubsection{Data collection procedure}

Since patent cooperation treaty (PCT) is the international treaty with more than 150 contracting states, it was considered the best source available for our research purposes. On the one hand, it makes it possible to seek patent protection for an invention simultaneously in a large number of countries by filing a single 'international' patent application instead of filing several separate national or regional ones. Figure 1 shows the 
operation of the PCT system (https:/www.wipo.int/pct/en/faqs/faqs.html) which includes:

- Filing an international application with a national or regional patent Office or WIPO, complying with the PCT formality requirements.

- International search: an 'International Searching Authority' (ISA) identifies the published patent documents and technical literature which may have an influence on whether the invention is patentable and establishes a written opinion on the invention potential patentability.

- International publication: after the expiration of 18 months from the earliest filing date, the content of the international application is disclosed to the world.

- Supplementary international search (optional): a second ISA identifies published documents which may not have been found by the first ISA (which because of the diversity of prior art in different languages and different technical fields).

- International preliminary examination (optional): one of the ISAs carries out an additional patentability analysis, usually on an amended version of your application.

- National phase: after the end of the PCT procedure, usually at 30 months from the earliest filing date of your initial application, from which you claim priority, you start to pursue the grant of your patents directly before the national (or regional) patent offices of the countries in which you want to obtain them.

Figure 1 Overview of the PCT system (see online version for colours)

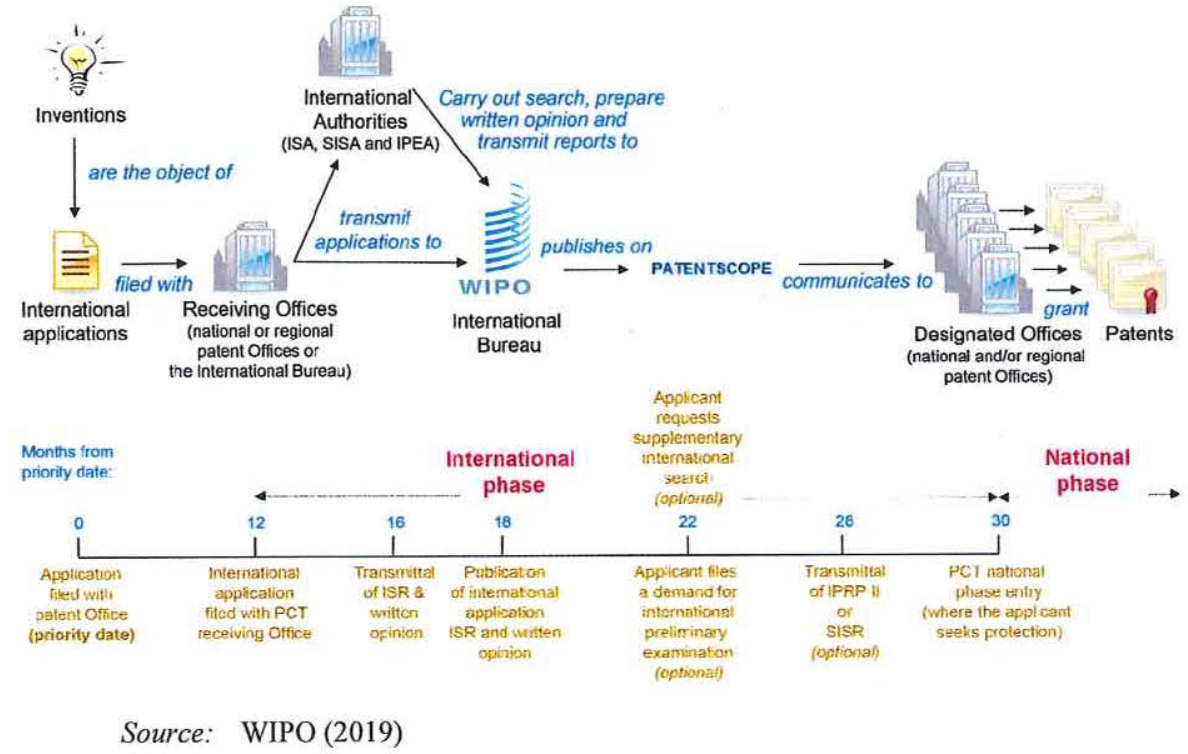

On the other hand, the work carried out by Lax Martínez et al. in 2016 for WIPO entitled 'Identifying the Gender of PCT inventors' is the first publication that analyses the identification of gender in the PCT system, at an entire and global level, and highlights the difficulty of accessing data on IP belonging to women. These authors have compiled 
a worldwide gender-name dictionary, which includes 6.2 million names for 182 different countries to disambiguate the gender of PCT inventors (Lax Martínez et al., 2016). The results of their work have been compiled and accepted by the WIPO, which has added this updated data to its official statistics and were first published in May 2019 and made available to the general public.

In short, our quantitative study is fuelled by these two sources to learn about patents and women in LATAM and IBER.

\subsubsection{Key informants and organisations with an interest in IP studies}

Key informants provided us access to sources of literature that electronic databases may not detect. Key informants and relevant organisations also included those related to countries such as Cuba, since there was no data available for some years. We also made a few enquiries to WIPO which clarified the situation for the authors. The online databases of WIPO was searched for relevant publications. In this sense, to check the available data on IP on the WIPO database related to female, the authors, through the form available on the statistics website, contacted the WIPO. On the first occasion, they confirmed that the only information available was in PCT, through indicators 13,14 and 15 . On the second occasion, they confirmed that there is no more data available crosschecking the variables 'gender and country'. On the third, they informed us that the statistics mentioned are 'estimations' and not 'real data', given that for the Lax Martinez et al. (2016) methodology was used for their own estimation.

This allowed us better to understand the published secondary sources when they were too general or ambiguous when presenting the data. Moreover, the online databases of organisations such as EUIPO (European Intellectual Property Office) were also checked, when possible, to contrast the information.

\subsubsection{Data used}

The WIPO official statistics offer a very large battery of indicators on different aspects of IP, both in monthly and annual series related to patent, trademark, industrial design, utility model, geographical indications, PCT, Madrid and the Hague. In relation to the research topic, WIPO official statistics offer three indicators for PCT related to the female gender and only shown in annual series and referred to PCT. The information contained in each of the aforementioned indicators is as follows: Indicators 13,14 and 15 contain the PCT data related to the aforementioned female gender and its calculation, the WIPO data is based solely on Lax Martínez et al.'s (2016) study. These authors compiled data on the participation of women in the PCT system from their 'given names', taking into account the particularities of each language. The three mentioned indicators on which this research is based are described below.

- Indicator 13 -Share of applications with at least one women inventor (yearly statistics) by countries. This indicator presents the percentage of applications presented by women inventors from 2000 to 2018 and grouped by country (data updated to June 2019).

- Indicator 14 -Share of applications with at least one women inventor by technology (annual statistics). This indicator presents the percentage of applications presented by women inventors (at least one woman) in the technology sector and grouped by type 
of technology. It does not provide data for different countries. Therefore, this indicator is not used in this study.

- Indicator 15 - Share of women inventors (yearly statistics). This indicator presents the annual data of the percentage of women inventors from the year 2000 to 2018 (data updated to June 2019) and separates them by country.

Of these three indicators, as can be seen in the detailed description of each, only 13 and 15 allow cross-country data. As regards the data offered by the WIPO in the available indicators, it should be noted that the WIPO, in response to our requests for information, confirms that these indicators are not proper 'data' but 'estimates' based on the methodology of Lax Martínez et al. (2016), as stated above. This is so, because when the patent registration is done there is no specific field to indicate the gender of the applicant or applicants.

Given the existing methodological restrictions to create the classification finally used, the WIPO uses the methodology of the work of Lax Martínez et al. (2016), which in turn has its own limitations, as warned by its authors. They only refer to those already detected, that the same first name can be masculine or feminine according to the language of origin (e.g., Rosario is a women's name in Spain but refers to men in Argentina), or vice versa, and also the same name can be both masculine and feminine according to the country (e.g., Andrea; a female and male name in Spain). It should also be added that in the data used, according to WIPO sources consulted by the authors, a 'missing' cell does not mean that there is no female inventor in the PCT registry, it means that 'there is no data', so that missing data cannot be replaced by zeros in the database since its interpretation would be distorted.

\subsubsection{Participants and sampling}

Criterion sampling has been used to select the participant countries who meet specified criteria. To identify and cluster the countries that are included in the study, the Royal Spanish Language Academy definition of the RAE (Royal Academy of the Spanish Language) has been taken as a reference: LATAM. This grouping includes the traditional Latin American countries and adds some areas such as: Haiti, Belize, Guadeloupe or French Guyana, among others. However, for the area under study and for the two selected variables (gender and country) WIPO only offers data for 13 countries (11 in Latin America and 2 in Iberia): Argentina (AR), Brazil (BR), Chile (CL), Colombia (CO), Costa Rica (CR), Cuba (CU), Ecuador (EC), Mexico (MX), Panama (PA), Peru (PE), Uruguay (UY), Portugal (PT) and Spain (ES). Thus, these 13 countries are the subject of our study. There is no data from other countries because they are not part of the PCT system. The remaining countries in the area are not integrated into the PCT system and therefore there is no data available to offer reliable results.

\subsubsection{Data analysis}

Next, statistical analyses have been carried out to achieve the objectives of the study using software SPSS v. 23 for Windows. A descriptive analysis of the data has been carried out comparing LATAM and IBER countries versus OTHER COUNTRIES of the world and a test for differences in proportions has been carried out using the chi-square statistic, with the Yates correction (Reynolds, 1984) and the Fisher's Exact Test 
(Díaz de Rada, 1999) in the event that the expected frequency in more than $20 \%$ of the observations was less than 5 . In addition, accompanying graphs created by the authors allow us to observe the data count (proportions) more accurately.

\section{Results}

\subsection{Qualitative analysis}

This section presents the results of a comprehensive revision of published literature on women's participation in the field of IP and its potential for gender equality.

\subsubsection{Women participation in intellectual property sourcing - key drivers of inequality}

Considering the bulk amount of literature that confirms that education is an instrumental yardstick to determine gender gap, we revised literature that focused on education opportunities for men and women as an essential requirement to reduce gender inequalities in IP sourcing. According to Casella and Coelho $(1995$, p.8) "It is necessary, therefore, to introduce gender perspective in the process of research project development, as a way to ensure women participation based on equity". Their substantive body work indicates that, although there are more women who graduate and also gain master degrees programs, interestingly, there are far fewer women who finish their $\mathrm{PhD}$ program and still fewer less of those who work as researchers. This phenomenon is known as the 'leaky pipeline' [Huyer, (2015), p.3].

In considering how such a phenomenon may extent to business, we found that although many companies that have gender egalitarian policies in place and that also care for of their employees in the field of CSR to promote and ensure equality between men and women and men, for authors such as Kaufmann (1999) and Writh (2002) there are women discrimination factors in these companies that make it difficult for them to reach managerial positions. Two groups of factors have been identified. They are:

a external factors, which refer to the environment in which the company operates

b internal factors, which encompass work procedures, organisational culture and the way people interact.

According to Dema (2007) these factors in turn cause two types of segregation: the horizontal, epitomised by 'men's jobs' and 'women's jobs' (in Europe, for example, companies in the cleaning sector usually have predominantly female staff, while in the US they are male) and; the vertical, exemplified by 'glass ceiling'. The latter refers to the small number of women who reach senior positions in organisations and is derived wage discrimination significance, in which women receive less remuneration for doing the same work than men (D'Alessandro, 2018).

On a point of women participation in corporate IP sourcing, Lax Martínez et al. (2016) consider that women who work in companies and corporations with hierarchical organisational structures tend to participate less in activities related to intellectual patents than men. This idea is supported by various authors who claim that when inventing, women tend to be part of more numerous research groups that men [Naldi et al., 2004; 
Busolt et al., 2008; European Studies on Gender Aspects of Inventions-Statistical Survey and Analysis of Gender Impact on Inventions (ESGI); Moody, 2004].

\subsubsection{Women participation in IP sourcing - the case of patents}

In examining the results of previous studies related to gender and its connection to patents, we found that the proportion of women who make use of the patent system is still low compared to the percentage of scientific articles that are published by each gender (Jung and Ejermo, 2014). Some scholars also relate this phenomenon to the aforementioned 'leaky pipeline' (Huyer, 2015). Burk (2018) holds a similar view and confirms that less than half of women scientists are likely to obtain a patent for their research as their male colleagues, both at the business and academic levels. In addition, he claims, it seems to exist in all ages and in all cohorts of women employed in the fields related to science, technology, engineering and maths (STEM). In contrast, we found that when comparing men and women importance of research (e.g., taking into account indicators such as research grants) these disparities do not exist. That is to say, when women's investigations do obtain patents, they can be as notable as those of men.

\subsubsection{Factors contributing to gender inequality in patent registry and early stage of innovation}

When examining the status of technology transfer and wealth creation from a gender perspective, for many people IP-based technology has no clear link to gender - there is a misconception that innovation factors, such as IP and technology transfer are gender neutral (EQUALS, 2019). In fact, far from being neutral, IP filing systems seem to be afflicted by gendered structural constraints -by the inherent bias of the approaches the IP system rely on. Moreover, while the form and impacts of IP use will be gendered, so will the discourse around it. A few observers have suggested that if some forms of IP-related decision-making are flawed because of, for example, bias and discrimination against women in the IP protection and commercial exploitation, then perhaps IP policies (assisted with effective transfer technology) can also help correct those flaws (Alunni, 2019). Reality shows that although, in some exceptional cases, strategic use of IP has helped women (particularly those who are well off) transform their individual situation it hasn't yet affected social systems of inequity.

A gender biased IP system, for example, can actually exacerbate existing gender inequalities in the IP- intensive fields (especially electrical and mechanical engineering) and in IP-intensive jobs (especially development and design) is perhaps one of the main sources of innovation's contribution to inequality. There is a responsibility hence to ensure that, at a minimum, IP-based technologies do not exacerbate existing gender inequalities. Through an unbiased IP system, it is argued that industry, civil society, and policy-makers can converge to achieve this goal.

One area of concern is the gender imbalance in IP-intensive fields, where men dominate. This simplified view excludes analysis based on intersectionality, such as women and men of different income groups, race, ethnicities or class. Some technology transfer managers believe that IP can improve some forms of economic growth that are distorted by, for instance, discrimination against women researchers/inventors to benefit from equal access to university support. Particularly, in emerging science and technology-related areas, where women's participation and recognition often seem to 
suffer from the same discriminatory patterns identified elsewhere in academia (Etzkowitz et al., 2000).

Some have expressed optimism about several mechanisms that prominent US universities (such as MIT, Harvard, Princeton, Stanford, Yale, California, Berkeley, Michigan and Pennsylvania) and have introduced to support institutions and individuals to empower women to participate fully in science and technology, as a consequence of "an increasing recognition that the lack of women at senior level of academe is often a systemic consequence of academic culture" [Rosser, (2003), p.6]. Nevertheless, most of the research aimed to examine the implications of boosting women's participation in IP sourcing, innovation and technology transfer focus mainly on high-income countries, thereby highlighting the lack research for the same topics devoted to the Global South.

One of the major challenges is the low level of women's participation in the IPintensive fields and industries. The resulting lack of diversity in IP sourcing and prototyping can produce a new wave of technical innovation (in ICT) that:

a fail to benefit from female talent and motivations to generate valuable ideas to tackle old and new problems - hence failing to meet the needs of all

b in spite of the technological advancement so far reached, will deny women the unique opportunity to reap the advantages of wealth creation from the digitised economy, thereby magnifying existing inequalities through uneven access and use of the ICTs.

For countries in the Global South this means not only that local IP protection and applications are mainly submitted and produced by men (Web Foundation, 2017), but also that - given the global dominance of high-income countries-based technology companies - the imported IP products and services are most likely produced by 'affluent white men' (Crawford, 2016). One of the consequences of this exclusion of women is various forms of discrimination (Buolamwini and Gebru, 2018).

The important feature of bias is its impact, not its motivation. In reviewing evidence of IP-based bias and discrimination, we have identified two distinct categories:

1 social norms and language - invisible barriers that lead to discrimination against women scientists, researchers, innovators or entrepreneurs

2 biased process - how IP filing systems can be altered depending on the gender of the inventor (in detriment of women) -realities that affect the advancement of a female idea to the market.

\section{Implicit sources of discrimination: social norms and language}

The issue of structural bias in equal access to university support has long been recognised. Friedman and Nissenbaum (1996) noted that this concern was not new; the most serious types of discrimination were systematic (not random), leading to unfair outcomes. Technical discrimination is based on the structural constraints of a system. In emerging science and technology-related areas, women's participation, advancement, and recognition often seem to suffer from the same discriminatory gender patterns identified elsewhere in academia (Etzkowitz et al., 2000). The Women Inventors Committee of the Association of University Technology Managers' (AUTM) states that the professionals working across continents to facilitate technology transfer all share one common 
challenge: a lack of women's participation in several aspects of the innovation process (WIC, 2018).

Handelsman et al. (2005) suggest that universities are failing to take advantage of an available resource, noting that the presence of women scientists in a particular field determines the proportion of women in faculty positions, and that this ratio lags far behind the proportion of $\mathrm{PhDs}$ granted to women. They identify, as reasons for this disparity, the impediments to recruitment, retention, and advancement of outstanding women scientists. Research is badly needed to examine the global implications of boosting women's participation in wealth creation through research discoveries and knowledge transfer to industry. This, points to the challenges that people in the Global South (particularly women) will face to make the IP creation more inclusive.

\section{Implicit sources of discrimination: biased process}

A second source of discrimination arises from the IP filing system, including how patents are obtained and maintained over time, although no explicit rules underlay the discriminatory treatment of women. Jensen et al. (2018) analysed a recent IP filing bulk data release with the histories of 2.7 million patents issued in the US between 2001 and 2014. Their analysis reveals how patent claims can be altered during the process of filing, depending on the gender of the inventors. Overall, women inventors' patents were more likely to be rejected than those filed by teams of men; even when applications were granted, women's patents progressed poorly, and fewer were maintained, because they received fewer citations by other inventors and from patent examiners (Jensen et al., 2018). This helps explain why, although women earn roughly $50 \%$ of the doctoral degrees in science and engineering in the USA, when it comes to patenting their inventions, they trail far behind men: only $10 \%$ of patent-holders are women.

Even in the life sciences, where women earn more than half of new PhDs, only $15 \%$ of inventors listed on patents are women. Rosser (2009) argues that, if women scientists and engineers face difficulties in obtaining patents, then woman are not equal participants in the newest areas and of science and technology; they are unable to serve as leaders in their fields, and they lose opportunities to profit both financially and through professional advancement.

Research is therefore in order to find ways to mask the applicant's identity and gender. One potential solution would be to make the IP filing process more anonymous, for example by listing only the inventors' initials; further exchanges between the applicants and the examiners could be restricted to a platform that ensures anonymity.

\subsubsection{Women participation in patent protection in LATAM and IBER}

According to Morales and Sifontes (2014) in most of the Latin America countries, there is still little information about research in science and technology specifically on gender. In analysing 2082 patents registered by Argentina, Brazil, Mexico, Colombia, Cuba, Peru, Chile and Venezuela in the USPTO between 1990 to 2006, the authors found that:

a $20 \%$ of the inventions do involve participation of females, particularly in the areas of chemistry and metallurgy

b the countries with the greatest gender inequality in the patent registry are Peru, Argentina and Mexico. 
These conclusions are of paramount importance to understand the trends in the registration of patents in the region and its gender perspective, although it corresponds to more than 15 years ago.

In order to compare Morales and Sifontes (2014) with a more recent source of information, we examined a recent study by WIPO (Mexicanist, 2019) and, although it does not look specifically at gender issues, it points out that the Latin American countries lack adequate policies to motivate females participation in productive sectors to increase their global contribution in the research in science and technology area. Adding that Latin America has grown considerably in industrial terms, but its scientific and technological contribution has led to a considerable fall in patents and other IP variants by business people and universities.

To understand what are the factors affecting LATAM and IBER from increasing their global contribution in the research in science and technology, we looked at a recent report (WIPO, 2019) which points out variables such as the average time it takes patent resolution, as well as rights of other IP property derivatives in Latin American countries. According to the WIPO the resolution process is extremely long, creating another factor to discourage interested parties from submitting applications. This is confirmed by the 2017 trends in patent application where: 3.17 million patent applications filed worldwide, represented a $5.8 \%$ more than the previous year. Out of these applications, $65.1 \%$ come from Asia, 31.5\% from Europe and North America, while Latin America and the Caribbean, Oceania and Africa all together barely added $3.4 \%$.

In Brazil, for example, completing the patent application process can take up to eight years, whereas in the European Union the process takes two years regularly, and in Russia only nine months. The report (WIPO, 2019) also reflects on positive country trends such as the case of Ecuador and Colombia, both rapidly growing in IP protection activity $(11.5 \%$ and $7.7 \%$ respectively). They clarify that those requests were made by foreigners residing in the country.

Since this report did not provide information regarding the gender variable, as in Latin America, much of the research in science and technology focus is on solutions to address local and national development challenges, such as improving health outcomes, public transportation, agricultural productivity, and access to financial services (Brandusescu et al., 2017), we also looked at alternative source to help reduce the existing gap in the literature.

The Web Foundation (2017) for example, sustain that in the Global South potential developmental impacts of strategic use of IP include creating new business opportunities for small and medium enterprises (including the creative industry or orange economy), preventing disease, deploying emergency services more efficiently, reducing illegal wildlife poaching, and improving mechanisms - for public consultation and decision-making. On a gender perspective, Buskens and Webb (2009) also note that these uses of IP can help individual women transform their situations, but they do not address social systems of inequity. Truly comprehensive strategic IP-based interventions, that aim to solve development challenges while improving outcomes for women more broadly, must begin by considering the inherent gender inequalities that underpin the social and political context in which IP-intensive fields and IP-based technologies evolve.

The above lead us to think that a starting point for this mission is to understand how IP schemes, if their benefits are not strategically deployed, can in fact exacerbate existing gender inequalities. In order to throw light on how IP is working in our targeted region, 
LATAM and IBER, the next section offers a quantitative analysis of PCT applications in comparing LATAM versus OTHER COUNTRIES.

\subsection{Quantitative analysis}

This section presents the results of the analysis of WIPO disaggregated data for women participation in PCT, focusing on the geographical area considered in this study.

Table 1 Applications with at least one women inventor: LATAM + IBER vs. OTHER COUNTRIES (years 2000 to 2018)

\begin{tabular}{|c|c|c|c|c|c|c|c|c|c|}
\hline & \multicolumn{3}{|c|}{$L A T A M+I B E R$} & \multicolumn{3}{|c|}{ OTHER COUNTRIES } & \multicolumn{3}{|c|}{ Total } \\
\hline & Media & $N$ & $\begin{array}{c}\text { Stand. } \\
\text { dev. }\end{array}$ & Media & $N$ & $\begin{array}{c}\text { Stand. } \\
\text { dev. }\end{array}$ & Media & $N$ & $\begin{array}{c}\text { Stand. } \\
\text { dev. }\end{array}$ \\
\hline 2000 & 14.75 & 4 & 8.539 & 19.71 & 41 & 9.389 & 19.27 & 45 & 9.336 \\
\hline 2001 & 17.00 & 4 & 6.481 & 18.27 & 45 & 8.664 & 18.16 & 49 & 8.459 \\
\hline 2002 & 32.14 & 7 & 31.045 & 19.02 & 49 & 8.828 & 20.66 & 56 & 13.869 \\
\hline 2003 & 25.00 & 9 & 29.052 & 21.13 & 47 & 8.757 & 21.75 & 56 & 13.746 \\
\hline 2004 & 28.88 & 8 & 29.638 & 21.20 & 50 & 9.848 & 22.26 & 58 & 14.084 \\
\hline 2005 & 30.75 & 8 & 25.359 & 22.10 & 50 & 10.570 & 23.29 & 58 & 13.567 \\
\hline 2006 & 29.00 & 9 & 20.518 & 22.00 & 52 & 10.282 & 23.03 & 61 & 12.340 \\
\hline 2007 & 35.63 & 8 & 25.906 & 23.85 & 55 & 11.012 & 25.35 & 63 & 14.036 \\
\hline 2008 & 38.13 & 8 & 25.654 & 21.91 & 57 & 10.867 & 23.91 & 65 & 14.287 \\
\hline 2009 & 40.88 & 8 & 25.085 & 24.08 & 53 & 13.284 & 26.28 & 61 & 16.095 \\
\hline 2010 & 23.88 & 8 & 11.569 & 22.20 & 61 & 11.075 & 22.39 & 69 & 11.059 \\
\hline 2011 & 28.75 & 8 & 9.254 & 23.21 & 56 & 10.169 & 23.91 & 64 & 10.159 \\
\hline 2012 & 26.00 & 9 & 11.554 & 25.36 & 59 & 12.605 & 25.44 & 68 & 12.391 \\
\hline 2013 & 34.91 & 11 & 24.485 & 24.24 & 58 & 9,939 & 25.94 & 69 & 13.654 \\
\hline 2014 & 28.18 & 11 & 11.044 & 23.72 & 60 & 10.903 & 24.41 & 71 & 10.967 \\
\hline 2015 & 27.33 & 9 & 9.605 & 24.93 & 61 & 10.907 & 25.24 & 70 & 10.714 \\
\hline 2016 & 28.44 & 9 & 12.768 & 25.75 & 60 & 11.088 & 26.10 & 69 & 11.255 \\
\hline 2017 & 31.00 & 10 & 10.220 & 26.69 & 61 & 11.166 & 27.30 & 71 & 11.072 \\
\hline 2018 & 34.08 & 12 & 19.252 & 26.22 & 60 & 9.883 & 27.53 & 72 & 12.137 \\
\hline
\end{tabular}

Note: The average value for each year refers to the average of the percentage of applications in which there is, at least, one woman inventor.

Source: Created by authors using WIPO statistics database. Last updated: June 2019

\subsubsection{Results on PCT applications submitted by women by geographical area (Indicator 13)}

Table 1 shows the percentage of patent applications submitted to the PCT, where at least a woman inventor is participating (Indicator 13). When comparing the percentages for the period between 2000 and 2018 between LATAM+IBER versus OTHER COUNTRIES we obtained that percentage of applications from LATAM+IBER ranges between $14 \%$ and $40 \%$; the year of pick being $2009(40 \%)$ with a sudden decline in $2010(23 \%)$ and substantial recovery in $2018(38 \%)$. The trend increases in time and outnumbers the 
aggregated percentage for OTHER COUNTRIES. In general, this indicates that patent applications from LATAM+IBER results are more inclusive than the rest of the world. This outcome, however, cannot be fully conclusive, as the patent data that generated these percentages for LATAM was limited in the number of applications by countries and interrupted for individual countries such as Cuba (for which the first number was recorded by WIPO in year 2000).

Table 2 Percentage of PCT publications in which there is at least one woman inventor: proof of differences in proportions of LATAM+IBER vs. OTHER COUNTRIES

\begin{tabular}{lccc}
\hline Year & Fisher's exact statistic & $N$ & Exact sign. (bilateral) \\
\hline 2000 & 31.161 & 45 & 0.488 \\
2001 & 30.538 & 49 & 0.403 \\
2002 & 24.074 & 56 & 0.885 \\
2003 & 30.169 & 56 & 0.224 \\
2004 & 23.645 & 58 & 0.855 \\
2005 & 27.580 & 58 & 0.253 \\
2006 & 35.752 & 61 & 0.346 \\
2007 & 32.345 & 63 & 0.653 \\
2008 & 33.735 & 65 & 0.174 \\
2009 & 33.920 & 61 & 0.221 \\
2010 & 38.958 & 69 & 0.220 \\
2011 & 36.146 & 64 & 0.258 \\
2012 & 39.196 & 68 & 0.291 \\
2013 & 35.572 & 69 & $0.080^{* *}$ \\
2014 & 39.192 & 71 & $0.013^{*}$ \\
2015 & 40.168 & 70 & 0.142 \\
2016 & 34.769 & 69 & 0.669 \\
2017 & 36.209 & 71 & 0.147 \\
2018 & 34.052 & 72 & 0.422 \\
\hline
\end{tabular}

Note: ${ }^{*}$ sign. between 95 and $99 \%,{ }^{* *}$ sign. $90 \%$.

For the data shown in Table 2, we took note that values lost in the database have been treated as lost by WIPO, because these values cannot be substituted by 0 . In order to establish how likely the observed distribution of percentages was due to a chance, we made use of the chi-square statistical analysis, with Yates correction, indicating that the statistics used are based, in all cases, with valid data in the ranges specified for all the variables involved. Given that it was just necessary to compare percentages, we created the corresponding contingency tables for each year and for both categories LATAM+IBER and OTHER COUNTRIES and used the most suitable statistical test to make this comparison. Nonetheless, considering that when the expected frequency of more than $20 \%$ of observations is less than 5, Reynolds (1984) advises not to use this statistic, and this was the case for all the years analysed, we also ran the Fisher's Exact Test as advised by Díaz de Rada (1999) in this case.

Fisher's Exact Test performed has shown that the percentages used are not statistically significant in most of the years analysed. This means that, although 
apparently the percentage of publications submitted to the PCT system is higher in the LATAM + IBER area compared to the rest of the world, it cannot be confirmed that this difference is a consequence of women having more patents in that area or elsewhere. In addition, given that the percentage data is based on estimates, and that the countries for which data inputs are very few, it is also risky to make a strong statement. What is clearly verifiable is that the patent publications in which at least one woman participates are still lower than those published for men in all the years analysed.

Figure 2 Evolution of the applications by women in LATAM+IBER (2000-2018) (see online version for colours)

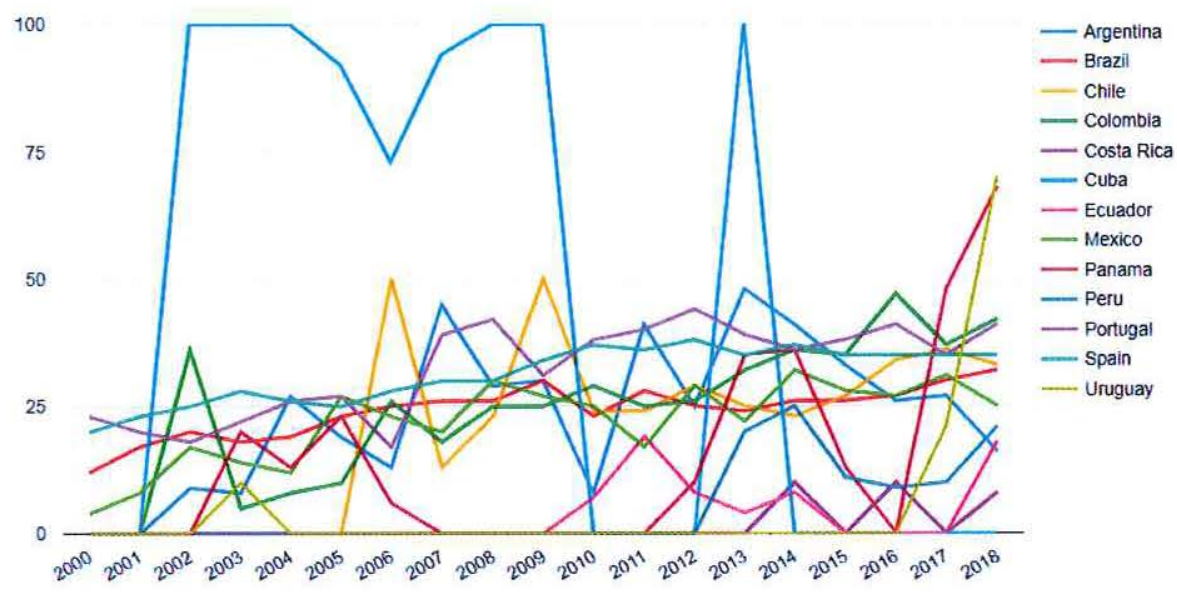

Source: Created by the authors from WIPO statistics database. Last updated: June 2019

Figure 3 Evolution without accumulation of the applications presented by women in LATAM+IBER (2000-2018) (see online version for colours)

500

375

50

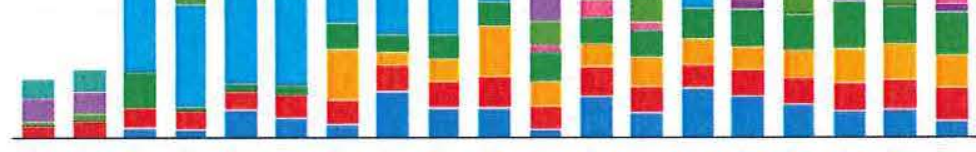

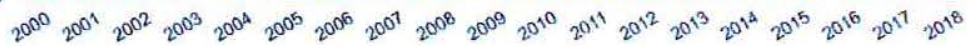

Source: Created by the authors from WIPO statistics database. Last updated: June 2019 
Next, Figures 2 and 3 show the evolution of Indicator 13. It is worth noting that the case of Cuba presents an abnormal trend (for some of the years with a percentage of circa $100 \%$, while for other years there is no data. This may be due to the fact that the data from which these figures have been constructed are estimates, which, as the WIPO has expressly confirmed to the authors of this article, it cannot be interpreted that the absence of data means that there is no female participant. Nevertheless, most countries maintain stable growth or evolution in their patent publications with at least one woman involved. From Figure 3, it can be noticed that the evolution of PCT patent publications in which there is, at least, one woman inventor, have steadily increased over the period considered, with decreases between 2010/2012 and 2014/2016. It shows that the evolution of patent applications submitted by women in LATAM and IBER countries between 2000 and 2018 has evolved in the same way for most countries, except for Uruguay and Panama whose patent application percentage within the region has increased notably in 2018 .

Figure 4 Evolution of the applications presented in which there is at least one woman in the TOP-6 countries (2000-2018) (see online version for colours)

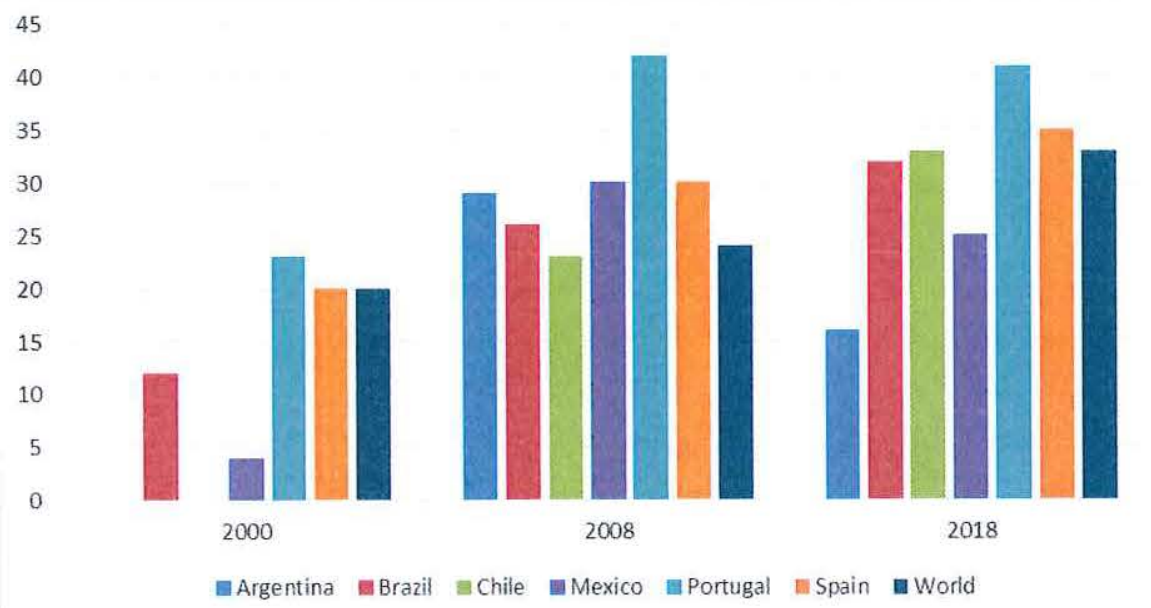

Source: Created by the authors from WIPO statistics database. Last updated: June 2019

Figure 4 shows the evolution for the TOP- 6 patent filing countries of LATAM and IBER between 2000 and 2018, where Portugal excels for the percentage of patent applications where at least one woman participates over the world average, followed by Spain, Chile and Brasil, which have an increase in the percentage of women inventors as the years progress, a trend that seems to be confirmed with what is happening in the world as a whole. A more erratic trend has been shown by Mexico, which presents a lower percentage of women inventors in 2018 compared to 2008, and Argentina, for which there was no even data in 2000 .

\subsubsection{Results on women inventors and geographical area (Indicator 15)}

Table 3 shows the results related to indicator 15 , corresponding to the percentage of women inventors by geographic areas. Here the LATAM + IBER area registers a 
percentage of women inventors higher than OTHER COUNTRIES, being $13.33 \%$ of women inventors throughout the world.

Table 3 Percentage of women inventors: LATAM+IBER vs, OTHER COUNTRIES (2000-2018)

\begin{tabular}{|c|c|c|c|c|c|c|c|c|c|}
\hline & \multicolumn{3}{|c|}{$L A T A M+I B E R$} & \multicolumn{3}{|c|}{ OTHER COUNTRIES } & \multicolumn{3}{|c|}{ Total } \\
\hline & Media & $N$ & $\begin{array}{l}\text { Stand. } \\
\text { dev. }\end{array}$ & Media & $N$ & $\begin{array}{c}\text { Stand. } \\
\text { dev. }\end{array}$ & Media & $N$ & $\begin{array}{c}\text { Stand. } \\
\text { dev. }\end{array}$ \\
\hline 2000 & 14.00 & 3 & 11.136 & 12.17 & 42 & 6.644 & 12.29 & 45 & 6.854 \\
\hline 2001 & 14.00 & 3 & 7.000 & 11.13 & 46 & 4.942 & 11.31 & 49 & 5.042 \\
\hline 2002 & 20.50 & 6 & 15.758 & 12.72 & 50 & 6.386 & 13.55 & 56 & 8.050 \\
\hline 2003 & 15.13 & 8 & 12.933 & 14.13 & 48 & 6.354 & 14.27 & 56 & 7.477 \\
\hline 2004 & 19.00 & 7 & 14.866 & 13.78 & 51 & 7.973 & 14.41 & 58 & 9.054 \\
\hline 2005 & 19.43 & 7 & 11.942 & 14.39 & 51 & 8.122 & 15.00 & 58 & 8.696 \\
\hline 2006 & 17.13 & 8 & 10.616 & 13.98 & 53 & 7.145 & 14.39 & 61 & 7.651 \\
\hline 2007 & 22.14 & 7 & 12.171 & 15.27 & 56 & 7.036 & 16.03 & 63 & 7.937 \\
\hline 2008 & 25.71 & 7 & 10.641 & 14.50 & 58 & 8.329 & 15.71 & 65 & 9.202 \\
\hline 2009 & 28.00 & 7 & 12.302 & 14.35 & 54 & 6.901 & 15.92 & 61 & 8.743 \\
\hline 2010 & 17.86 & 7 & 5.928 & 14.34 & 62 & 7.731 & 14.70 & 69 & 7.607 \\
\hline 2011 & 22.00 & 7 & 9.487 & 14.44 & 57 & 6.445 & 15.27 & 64 & 7.152 \\
\hline 2012 & 17.50 & 8 & 8.000 & 15.50 & 60 & 8.200 & 15.74 & 68 & 8.144 \\
\hline 2013 & 23.20 & 10 & 12.309 & 15.53 & 59 & 7.074 & 16.64 & 69 & 8.375 \\
\hline 2014 & 20.10 & 10 & 10.049 & 14.82 & 61 & 6.389 & 15.56 & 71 & 7.169 \\
\hline 2015 & 19.63 & 8 & 7.689 & 15.37 & 62 & 7.446 & 15.86 & 70 & 7.542 \\
\hline 2016 & 18.00 & 8 & 7.874 & 15.92 & 61 & 7.555 & 16.16 & 69 & 7.563 \\
\hline 2017 & 19.11 & 9 & 5.840 & 17.03 & 62 & 7.706 & 17.30 & 71 & 7.492 \\
\hline 2018 & 21.09 & 11 & 7.687 & 16.85 & 61 & 6.665 & 17.50 & 72 & 6.944 \\
\hline
\end{tabular}

Note: The average value for each year refers to the average percentage of women inventors.

Source: Created by authors using WIPO statistics database. Last updated: June 2019

Table 4 shows the results of the differences in proportions test performed on the data obtained from Indicator 15, the percentage of women inventors, from 2000 to 2018 and grouped into two categories, LATAM + IBER vs. OTHER COUNTRIES. As indicated above, in all cases the values lost in the database have been treated as lost (since the WIPO has confirmed to the authors of this article that they cannot be replaced by 0 ). The statistics in the tables are based on all cases with valid data in the ranges specified for all the variables of the tables. Also, given that it compares percentages, we have created the corresponding contingency table for each year and both categories LATAM+IBER vs. OTHER COUNTRIES. To make the comparison, the most suitable statistic is the chisquare, with the Yates correction. However, given that in our case the expected frequency of more than $20 \%$ of observations is less than 5, we have followed the Reynolds recommendations of (1984) to use Fisher's Exact Test (Díaz de Rada, 1999). 
Table 4 Proof of differences in proportions LATAM+IBER vs. OTHER COUNTRIES: percentage of women inventors

\begin{tabular}{lccc}
\hline Year & Fisher's exact statistic & $N$ & Exact sign. (Bilateral) \\
\hline 2000 & 30,003 & 45 & $0.014^{*}$ \\
2001 & 25,393 & 49 & $0.049^{*}$ \\
2002 & 21,264 & 56 & 0.241 \\
2003 & 26,544 & 56 & 0.109 \\
2004 & 28,646 & 58 & 0.121 \\
2005 & 24,863 & 58 & 0.495 \\
2006 & 24,361 & 61 & 0.695 \\
2007 & 33,263 & 63 & $0.055^{* *}$ \\
2008 & 33,129 & 65 & $0.014^{*}$ \\
2009 & 30,700 & 61 & $0.003^{*}$ \\
2010 & 23,561 & 69 & 0.630 \\
2011 & 29,893 & 64 & $0.093^{* *}$ \\
2012 & 27,235 & 68 & 0.382 \\
2013 & 33,578 & 69 & $0.015^{*}$ \\
2014 & 34,299 & 71 & $0.006^{*}$ \\
2015 & 29,886 & 70 & $0.005^{*}$ \\
2016 & 32,771 & 69 & $0.011^{*}$ \\
2017 & 26,005 & 71 & 0.291 \\
2018 & 29,498 & 72 & $0.029^{*}$ \\
\hline
\end{tabular}

Note: *sign. between 95 and $99 \%$, **sign. $90 \%$.

Figure 5 Share of women inventors LATAM+IBER VS. NO LATAM/IBER (year 2000 to 2018) (see online version for colours)

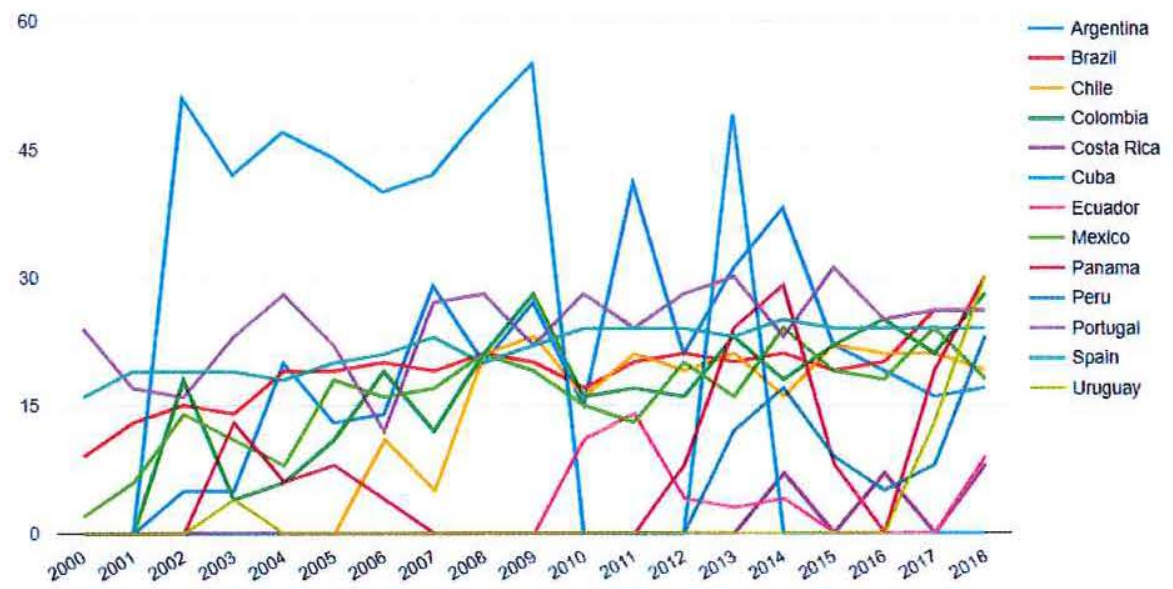

Source: Created by the authors from WIPO statistics database. Last updated: June 2019 
The outcomes of the test show statistical significance in many of the years analysed, which means that, although apparently the percentage of publications submitted to the PCT system is higher in the LATAM + IBER area compared to the rest of the world, yet it cannot be confirmed as true for all years examined. However, it is possible to affirm that women inventors are still a lower proportion than men in all the years considered and in both geographical areas.

Figure 6 Evolution of women inventors by LATAM+IBER countries (2000-2018) (see online version for colours)

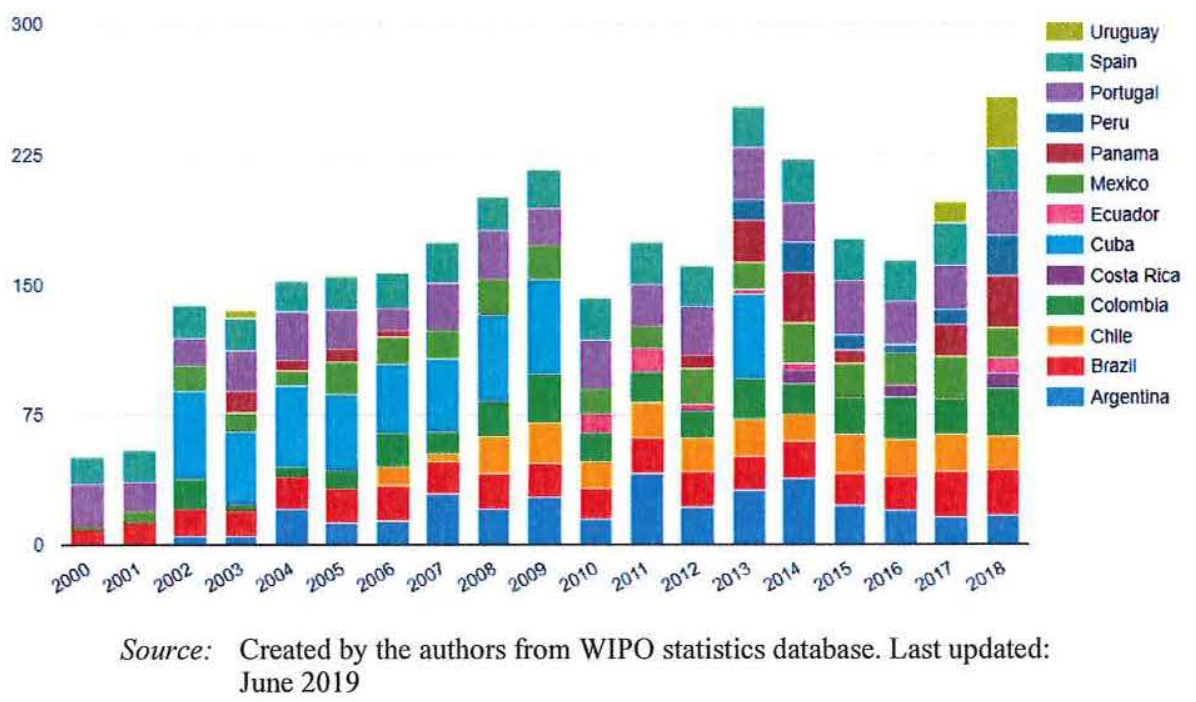

Figure 7 Evolution of women inventors by TOP-6 countries (2000-2018) (see online version for colours)

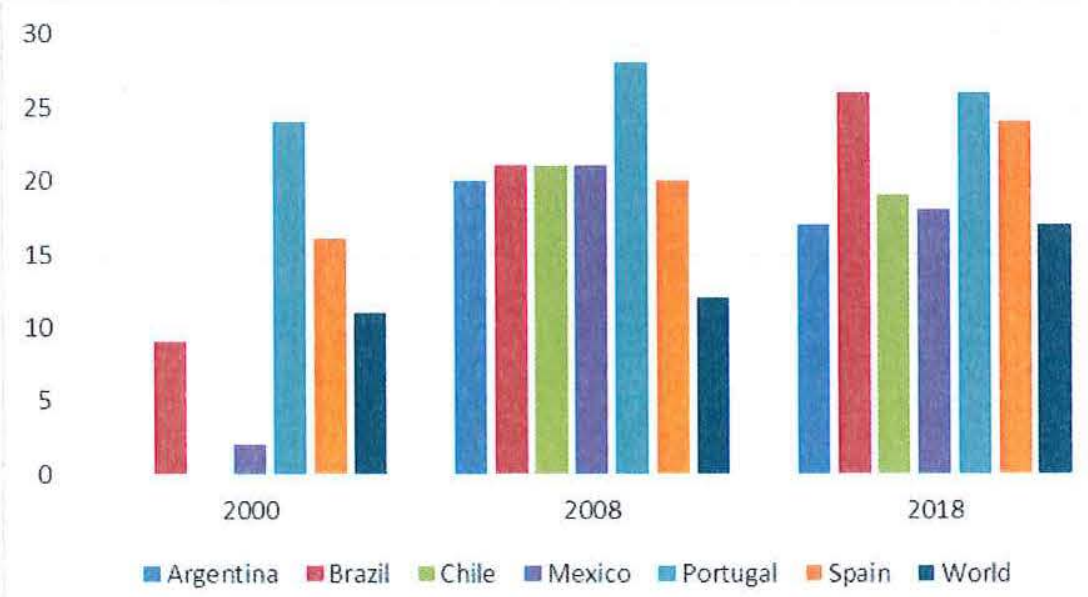

Source: Created by the authors from WIPO statistics database. Last updated: June 2019 
As can be seen in Figure 5, in 2000 Spain ranked in second position among all the countries considered and has dropped many positions by 2018. The position of Cuba is surprising, being ranked number one in 2000, but not showing any data for 2018 . However, Uruguay's position is very remarkable, since, in 2018, it moved from last to first place. Another perspective is offered by Figure 6, which shows the evolution by countries without accumulation.

Figure 7 shows the evolution of the TOP 6 countries of LATAM+IBER presenting more patents among the whole group. It clearly emerges that for the three periods selected, Portugal stands out in terms of the percentage of women inventors. It is also noteworthy that in both 2008 and 2018, all the countries in the selected area have a percentage of women inventors that is much higher than the world average.

Next, Figure 8 shows a WIPO summary of women inventors by large geographical areas, that can be seen in the latest publication on PCT (2019).

Figure 8 Share of women among listed inventors in PCT application by geographical region (2008, 2013 and 2018) (see online version for colours)

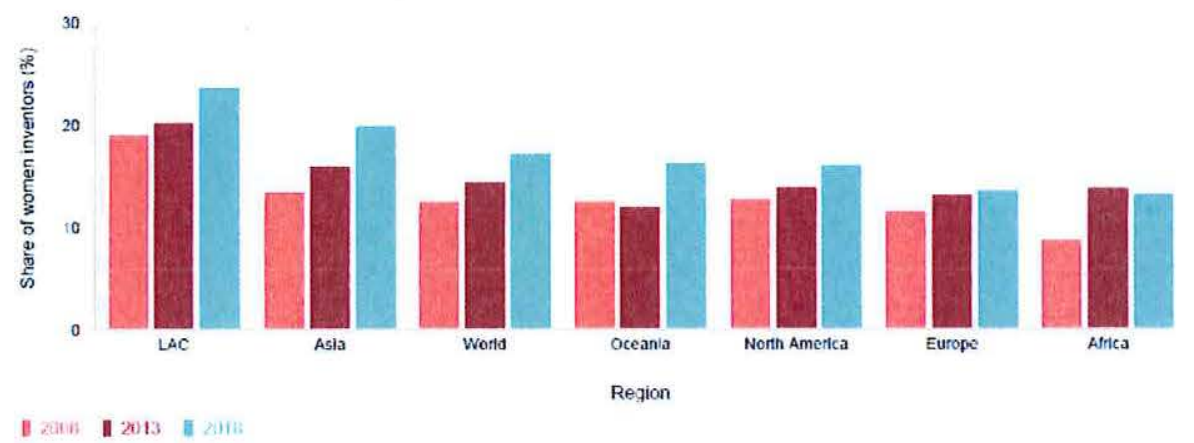

Note: LAC. Latin America and The Caribbean

Source: Patent Cooperation Treaty Yearly Review 2019 (March 2019 updated data)

Figure 9 Share of women among listed inventors and share of PCT with at least one woman as inventor for the top 20 origins, 2018 (see online version for colours)

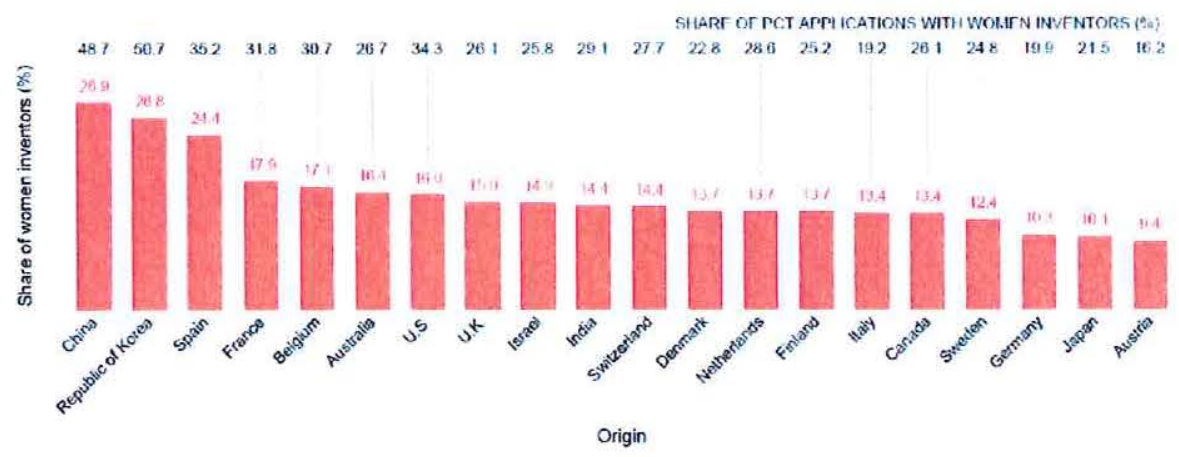

Source: Patent Cooperation Treaty Yearly Review 2019 (March 2019 updated data) 
As can be seen in the previous graph, in the three years that are shown, the area called LAC exceeds the average of the rest of the studied areas, without considering the participation of Spain and Portugal. In Figure 9 we can see, for several countries, the participation of women inventors and applications to PCT presented by women.

As can be seen in Figure 9, which presents the data for the top origins, Spain's position stands out from the other countries, being in third position in both variables (women being $24 \%$, behind China with $28.9 \%$ and the Republic of Korea with $26.8 \%$ ).

\section{Discussion and conclusions}

Since the main objective of this research was to analyse the issue of women's participation in IP creation and registration in LATAM and IBERIA and its potential for gender equality, after examining a raft of relevant documents on this topic, we can confirm that there is still a significant gap in the existing literature on the gender implications of IP sourcing and little discussion in relation to the socio-economic impact that this gender gap may have in the innovation process. On a point of data, we found also a large gap in disaggregated data by gender on patents -and IP in general - which prevents researchers from bringing evidence to their work. This gap widens when the focus moves from high income countries to the global south, in which the majority of countries tend to have just recent and interrupted data or not disaggregated data at all.

Nevertheless, the outcomes of our qualitative and quantitative analysis have proven of great value to nurture discussion in the attempt to, first, answer the conceptual questions about what the factors affecting women's involvement in the IP sourcing process are; and, on the assumption that if these factors are recurrent throughout the IP creation and protection process, will the impact of these factors be cumulative and incremental with the ensuing erosion of women's interest in IP related fields and jobs in the future? Identifying the specific factors responsible for the current shortage of women's involvement in the IP industry in LATAM and Iberia can be a valuable resource for policy makers in the effort to address the issues of the low participation of women in the IP industry and its implications, since as suggested by Schwartz 'women's issues are really business issues' (Shwartz and Zimmerman, 1992).

Following on from that, we present the status of the main findings produced by our literature review on the main factors affecting women's involvement in IP sourcing, in an effort to determine what has substantially changed and what has not yet. We found that the gender gap is still palpable in terms of patents and this has been observed across the five continents, though, with better results in Latin America and Iberia than in the rest of the world. In particular, the position of Spain among the listed inventors is outstanding as well as its share of PCT with at least one woman as inventor for the top 20 origins.

The IP-based technologies and IP-intensive industries will co-evolve with existing inequalities, particularly for countries in the Global South. In relation to how females' participation in science and technology (IP creation, protection and commercial exploitation) might improve or worsen gender equality, most of the evidence suggests that IP schemes (for IP creation, protection and commercial exploitation) are indirectly or directly exacerbating existing gender inequalities. Even where there is no harm or discrimination created by the process itself, gender discrimination leads to disproportionately negative impacts on women and, as a consequence, on innovation for society in general. This points to the importance for policy-makers, practitioners, and 
researchers to act now. A starting point is to discard the notion that IP is gender-neutral, and, rather, to acknowledge and incorporate analysis on gender throughout the IP policy process. Research is necessary to build an evidence base on the relationships between diffusion of IP creation/protection and gender inequalities.

The various examples highlighted throughout the research point to a broad range of research needs, both for those working in the field of IP and those studying its impacts. While recognising the impact that IP is already having on the economy globally, and more specifically in the Global South, we have put forward recommendations in three key areas. Much of this impact can be negative, as our examples illustrate. However, problems linked to gender inequalities may be overlooked in societies where the dominant narrative focuses on those in power, namely men. Policy-makers and researchers everywhere must recognise, and be prepared to articulate, that no country can achieve its national development goals as long as gender inequality persists.

According to our literature, explicit hurdles have been increasingly downplayed in academia, particularly with the introduction of inclusive policies by prominent universities (in the US, for example). This is an extraordinary breakthrough, considering that women's contribution to IP sourcing is rooted in academia due to the role that research plays between inventive ideas and IP commercialisation. We have also found that in private companies - where hierarchical structures prevail - gender vertical segregation is still recurrent and contributing to an increase in both the 'leaky pipeline' and 'glass ceiling', while causing cumulative effects on women's performance, innovatory talent and being conducive to lower levels of adoption and implementation of new technologies in general. In fact, we found that organisations featuring more equal participation of women tend to be more successful in their innovation and implementation efforts. In fact, as De Barbieri (1993) cogently indicates, it is essential to recover the contributions of women in society and culture to make them visible in creation (scientific in the case of patents), in daily life and, of course, in the history.

At the empirical level, we also managed to obtain valuable indications from the quantitative analysis carried out. In particular, we managed to extract from PCT indicators 13,14 , and 15 projections for disaggregated data on patent per gender and answers for individual countries to our preliminary questions about what the level of women involvement in patent filing in LATAM and Iberia is; and what the trends are indicating. The indications are that this quantitative analysis project satisfies the objectives of this research and throws light on future research which is still required. In particular, our analysis corroborates 3 important issues related to the gender gap in terms of IP:

The first, refers to the lack of gender disaggregated data in the different steps of the IP application and protection published by the WIPO, which not only refers to the patent process but also to that of trademarks, Industrial Designs, Utility model, Geographical Indications, PCT, Madrid, Hague. This consideration came about after thoroughly checking the WIPO statistics service and duly consulting WIPO officials on how we could best obtain data on the participation of women in the IP. Hence, out of a total of 128 Indicators contemplated by the PCT System, there are only three gender-related Indicators that provide gender disaggregated data in the form of estimates (i.e., not $100 \%$ real data but measured as a percentage of the total). On the one hand, it clearly indicates the enormous effort on which the WIPO is embarking to make available, as much as possible, gender disaggregated data through its statistical service, since there is even no specific field for gender when making a search. On the other hand, it also highlights that 
the underpinning issue is the still astounding low participation of women in IP sourcing in the PCT system in general for the entire period considered (2000-2018).

The second refers to the specific region of LATAM and Iberia. For example, we found that although the participation of women in the PCT system is greater than in the rest of the world, this primacy hasn't been sufficient for decision-makers from the regions to lead in IP policy inclusion to favour the IP industry as an opportunity to boost economic growth while addressing an unfounded social problem. This serious weakness is clearly proven by the figures, i.e. if we look at the 2017 trends in patent application, we can see that out of the 3.17 million patent applications filed worldwide, $65.1 \%$ come from Asia, 31.5\% from Europe \& North America, while Latin America and the Caribbean, Oceania and Africa all together barely added $3.4 \%$.

The third is linked to the first since it refers to the percentage of women inventors, where, in contrast with the higher percentages found for women's participation in IP in LATAM+IBER, the data indicates a lower percentage of women than men in all the years analysed, in all countries, and, thus, for the world as a whole (see Table 3 ).

After seeing these trends, it is natural to go back to our initial question: What has then changed? Here is what the evidence shows:

1 A closer look at the countries having more patents filed in LATAM+IBER, the percentage of women inventors tend to be much higher in those countries that have more patent publications in LATAM+IBER countries, i.e. for the TOP-6 the percentage of women involved was greater compared to the other countries in the same region and the world average (see Figure 7).

2 When it comes to the IBERIA countries, Portugal stands out regarding the percentage of women inventors and, although Spain registered more patents, its position in terms of women inventors remains third, behind China and the Republic of Korea (see Figure 9).

3 A further aspect to consider from this quantitative analysis refers to the methodological challenges that this research faced, particularly related to the data used to create tables and exhibits in the quantitative analysis which is based on WIPO estimates (and not real data) obtained from the WIPO methodology developed by Lax Martínez et al. (2016).

Nevertheless, we firmly consider that the outcomes have proven to be of great value to achieve the arguments presented in this section, which satisfy the objectives of this research and provide light for future research in this field, for example, an interesting area for future research can involve the testing of causality among PCT indicators based on estimates and real data results as this research lends itself to alternative quantitative methods to determine women's participation in the patent creation and protection process and the empirical relationships between its variables, on the assumption that more real disaggregated data will become available for future researchers.

\subsection{Suggested actions to be adopted}

In view of the challenges examined here being vast, but strategic interventions by both policy-makers and IP specialised agencies being able to make a difference, we present three key recommendations: 


\subsubsection{IP policy formulation}

Policies for IP creation, protection and successful commercialisation need to recognise that no IPR-intensive technology is gender-neutral (Alozie and Akpan-Obong, 2017; Nass et al., 1997; Wajcman, 2004). Developing gender-responsive policy is important to ensure that the impacts of IP on both women and men are critically assessed. A comprehensive gender-responsive national and institutional IP policy would create a broad understanding of how gender-based inequalities are maintained in society. Awareness can start with conversations about the roles of men and women in society and the kinds of inequalities women face, particularly through indirect and systemic forms of discrimination. The government can initiate these discussions in the public sector through consultations, workshops, and internal gender audits.

\subsubsection{Multi-stakeholder partnerships}

Governments should coordinate with academia and industry groups to generate accurate and timely data on the participation of women in the IP-intensive fields and industries (Campolo et al., 2017). Governments should also work with industry and other partners to fund women-owned firms working on IP-based technologies, and to incentivise firms generally to have more diverse staff at all levels (Web Foundation, 2018). Other public-private investments can support interdisciplinary research on career development in the field of IP protection and commercialisation (including gender inequalities), and sponsor STEM training and development programmes targeting women and girls. It is also important to promote networking and mentoring support for women and girls through outreach. In Latin America, for example, the main factors affecting the gender gap in internet use to accelerate progress towards the achievement of the sustainable development goals (SDGs) contained in the UN's 2030 Agenda for Sustainable Development shows that in the five Latin American countries surveyed (Argentina, Colombia, Peru, Paraguay and Guatemala) there is the lowest gender gap of the 17 countries surveyed from the Global South. Although overall mobile penetration is lower in Colombia than its Latin American counterparts, it has gender parity in mobile ownership.

\subsubsection{Improving the research agenda and IP development process}

The challenge for IP sourcing and commercialisation represents an opportunity in 'IP for development', one that is driven by actors in the Global South, who will also lead in identifying and implementing solutions to local challenges including gender inequality (Escobar, 2011). Inventors' decisions to disclose and protect their innovative ideas are critically important to avoid repeating the pattern seen in ICT4D, for example, as a field that has often excluded gender (Hafkin and Huyer, 2006). IP related agencies (WIPO, EPO, EUIPO and NPO among others) should start by asking how their solution serves to boost gender equality - or how they are making it worse. IP protection offices need to employ an 'unbiased IP filing process' approach (Hajian et al., 2016). The members of the IP scientific community in a particular country should collaborate on developing such an approach (by building on research networks in the Global South and elsewhere). Participatory design requires the inclusion of diverse groups (including those of women) throughout the IP policy design process to address gender-related issues. As in the examples mentioned above, there are several possible scenarios where a woman may 
want to bring legal action against a party because of gender-based discrimination. However, most legal systems require evidence of intent to discriminate, in order to rule against the discriminating party, and as we have already noted, many of the effects of IP-based discrimination are unintentional (Barocas and Selbst, 2016). In recognising the limitations of their legal systems in providing recourse for these types of discrimination, governments will have to develop alternatives for women and others in these situations. This can include for example, mandatory bias audits for consequential decision-making.

The limitations of the study include a lack of some industries and country sources. More detailed documents which are extremely expensive could have also helped us to complete the conclusions. As desk research, data is adequate preparation for only part of the information sought in the study. Primary research would have completed the investigation.

\section{References}

Alozie, N.O. and Akpan-Obong, P. (2017) 'The digital gender divide: confronting obstacles to women's development in Africa', Development Policy Review, Vol. 35, No. 2, pp.137-160, http://dx.doi. org/10.1111/dpr.12204.

Alunni, A. (2019) Innovation Finance and Technology Transfer: Funding Proof-of-Concept, Routledge, Oxford, UK.

Barocas, S. and Selbst, A.D. (2016) 'Big data's disparate impact', California Law Review, Vol. 104, No. 3, p.671, http://dx.doi.org/10.15779/Z38BG31.

Bell, A., Chetty, R., Jaravel, X., Petkova, N. and Van Reenen, J. (2019) 'Who becomes an inventor in America? The importance of exposure to innovation', The Quarterly Journal of Economics, Vol. 134, No. 2, pp.647-713, https://doi.org/10.1093/qje/qjy028.

Brandusescu, A., Ortiz, J. and Thakur, D. (2017) Artificial Intelligence: Starting the Policy Dialogue in Africa, World Wide Web Foundation, Washington, DC.

Buolamwini, J. and Gebru, T. (2018) 'Gender shades: Intersectional accuracy disparities in commercial gender classification', in Conference on Fairness, Accountability and Transparency, pp.77-91.

Burk, D. (2018) Cómo colmar la brecha de género en el ámbito de la propiedad intellectual, OMPI (Organización Mundial de la Propiedad Intelectual)/Revista [online] https://www.wipo.int/wipo_magazine/es/2018/02/article_0001.html (accessed April 2019).

Buskens, I. and Webb, A. (Eds.) (2009) African Women and ICTs: Investigating Technology Gender and Empowerment, Zed Books, London \& New York.

Busolt, U., Kugele, K. and Tinsel, I. (2008) European Studies on Gender Aspects of Inventions-Statistical Survey and Analysis of Gender Impact on Inventions (ESGI), Furtwangen im Schwarzwald, Germany.

Campolo, A., Sanfilippo, M., Whittaker, M. and Crawford, K. (2017) AI Now 2017 Report, AI Now Institute, New York University, New York.

Casella, K. and Coelho, M. (1995) Guía para la elaboración de proyectos con género, pp.1-8, Consejo nacional de la mujer, UNICEF Argentina [en línea] [online]. http://www.bantaba.ehu.es/ (accessed 30 Mayo 2016).

Castillejo, G. (2011) Marketing dirigido a la mujer: un inmenso mercado que presenta grandes desafios [Marketing directed to women: an inmense market that has big challenges] [online] http://www.marketingnews.es/varios/opinion/1061703028705/marketing-dirigido-mujerinmens 0.1.html (accessed April 2019). 
Cooke, E., Hastings, G. and Anderson, S. (2002) Desk Research to Examine the Influence of Marketing and Advertising by the Alcohol Industry on Young People's Alcohol Consumption, Research prepared for the World Health Organization, University of Strath-clyde, Centre for Social Marketing, Glasgow.

Council of Europe (1998) Mainstreaming de género. Marco conceptual, metodología y presentación de buenas prácticas, Consejo de Europa, Estrasburgo.

Crawford, K. (2016) 'Artificial intelligence's white guy problem', The New York Times, Sunday Review,25 June [online] https://www.nytimes.com/2016/06/26/opinion/sunday/artificialintelligences-white-guy-problem.html (accessed April 2019).

D'Alessandro, M. (2018) Economía Feminista. Las mujeres, el trabajo y el amor, Ediciones B, Barcelona.

De Barbieri, T. (1993) 'Sobre la categoría género: una introducción teórico-metodológica', Debates en sociología, No. 18 , pp.145-169.

de Beauvoir, S. (1949) Le deuxième sexe, Éditions Gallimard, Paris.

Dema, M.S. (2007) 'La introducción de la perspectiva de género en el marketing: una nueva forma de analizar las relaciones de intercambio', Estudios sobre Consumo, Vol. 81, pp.55-69.

Díaz de Rada, V. (1999) Técnicas de análisis de datos para investigadores sociales, Aplicaciones prácticas con SPSS para windows, Ra-Ma, Madrid.

EQUALS (2019) A Gender Perspective on Technology Transfer and Wealth Creation, March, Chapter 11, pp.322-328, The Inaugural Report of EQUALS Research Group, United Nations University Institute on Computing and Society (UNU-CS), Macau.

Escobar, A. (2011) Encountering Development: The Making and Unmaking of the Third World, Princeton University Press, Princeton.

Etzkowitz, H., Kemelgor, C. and Uzzi, B. (2000) Athena Unbound: The Advancement of Women in Science and Technology, Cambridge University Press, Cambridge, UK.

Friedman, B. and Nissenbaum, H. (1996) 'Bias in computer systems', ACM Transactions on Information Systems (TOIS), Vol. 14, No. 3, pp.330-347, http://dx.doi.org/10.1145 1230538.230561 .

Frietsch, R., Haller, I., Funken-Vrohlings, M. and Grupp, H. (2009) 'Gender-specific patterns in patenting and publishing', Research Policy, Vol. 38, No. 4, pp.590-599.

Hafkin, N. and Huyer, S. (Eds.) (2006) Cinderella or Cyberella? Empowering Women in the Knowledge Society, Kumarian Press, Connecticut.

Hague, P.N., Hague, N. and Morgan, C.A. (2004) Market Research in Practice: A Guide to the Basics, Chapter 3, pp.32-47, Desk Research, Kogan Page Publishers, London, UK.

Hajian, S., Bonchi, F. and Castillo, C. (2016) 'Algorithmic bias: From discrimination discovery to fairnessaware data mining', in Proceedings of the 22nd ACM SIGKDD International Conference on Knowledge Discovery and Data Mining, pp.2125-2126, ACM.

Handelsman, J., Cantor, N., Carnes, M., Denton, D., Fine, E., Grosz, B. and Sheridan, J. (2005) 'More women in science', Science, Vol. 309, No. 5738, pp.1190-1191.

Heikkilä, J. (2019) 'IPR gender gaps: a first look at utility model, design right and trademark filings', Scientometrics, Vol. 118, No. 3, pp.869-883, https://doi.org/10.1007/s11192-0182979-0.

Hoisl, K. and Mariani, M. (2017) 'It's a man's job: income and the gender gap in industrial research', Management Science, Vol. 63, No. 3, pp.766-790.

Huyer, S. (2015) Is the Gender Gap Narrowing in Science and Engineering?, Chapter 3 in UNESCO Science Report: towards 2030, France.

Instituto de la Mujer (2007) Estrategias de Mainstreaming de Género en el Ámbito de las Organizaciones Laborales y la Negociación Colectiva, Ministerio de Trabajo y Asuntos Sociales, Madrid.

Jensen, K., Kovacs, B. and Sorenson, O. (2018) Why Do Women Inventors Win Fewer Patents? Yale Insights, New Haven, Connecticut, USA. 
Jung, T. and Ejermo, O. (2014) 'Demographic patterns and trends in patenting: gender, age, and education of inventors', Technological Forecasting and Social Change, July, Vol. 86, pp.110-124.

Kaufmann, A. (1999) 'Tercer milenio y liderazgo femenino', in Nuño, G.L. (Ed.): Mujeres: de lo privado a lo público, pp.177-186, Tecnos, Madrid.

Khan, B.Z. (2000) 'Not for ornament': patenting activity by nineteenth-century women inventors', Journal of Interdisciplinary History, Vol. 31, No. 2, pp.159-195.

Lagarde, M. (1996) Género y feminismo. Desarrollo humano y democracia, Cuadernos inacabados, Madrid.

Lax Martínez, G., Raffo, J. and Saito, K. (2016) Identifying the Gender of PCT Inventors, p.33, World Intellectual Property Organization-Economics and Statistics Division, Geneva, Switzerland.

Lefeuvre, B., Raffo, J., Saito, K. and Lax Martínez, G. (2018) Las mujeres y el sistema internacional de patentes: tendencias alentadoras, OMPI [online] https://www.wipo.int/wipo_magazine/es/2018/02/article_0008.html (accessed April 2019).

LOU 6/2001 Ley Orgánica 6/2001, de 21 de diciembre, de Universidades, Jefatura del Estado «BOE» núm. 307, de 24 de diciembre de 2001 Referencia: BOE-A-2001-24515 [online] https://www.boe.es/buscar/pdf/2001/BOE-A-2001-24515-consolidado.pdf (accessed April 2019).

Mattelart, M. and Reader, K. (1982) 'Women and the cultural industries', Media, Culture \& Society, Vol. 4, No. 2, pp.133-151.

Mauleón, E. and Bordons, M. (2006) 'Productivity, impact and publication habits by gender in the area of Materials Science', Scientometrics, Vol. 66, No. 1, pp.199-218.

Mexicanist (2019) Creating Intellectual Property in Latin America is Expensive, Difficult and Time-Consuming [online] https://www.mexicanist.com/l/intellectual-property-in-latinamerica/ (accessed 21 Abril 2019).

Monreal-Gimeno, C. and Martínez-Ferrer, B.M. (2010) 'Esquemas de género y desigualdades sociales', in Internvención social y género, Vol. 99, pp.73-96, Narcea.

Moody, J. (2004) 'The structure of a social science collaboration network: disciplinary cohesion from 1963 to 1999', Am. Sociol. Rev., April, Vol. 69, pp.213-238.

Morales, R. and Sifontes, D. (2014) 'Desigualdad de género en ciencia y tecnología: Un estudio para América Latina', Observatorio Laboral Revista Venezolana, Vol. 7, No. 13, pp.95-110.

Moreno, E. (2000) 'La transición de modelos sexistas en la escuela', in Santos, M.A. (Ed.): El harén pedagógico, Graó, Barcelona.

Naldi, F. and Parenti, I.V. (2002) Scientific and Technological Performance by Gender: A Feasibility Study' on Patent and Bibliometric Indicators, Office for Official Publications of the European Communities. Luxembourg.

Naldi, F., Luzi, D., Valente, A. and Parenti, I.V. (2004) 'Scientific and technological performance by gender', in Handbook of Quantitative Science and Technology Research, pp.299-314, Springer, Dordrecht.

Nass, C., Moon, Y. and Green, N. (1997) 'Are machines gender neutral? Gender-stereotypic responses to computers with voices', Journal of Applied Social Psychology, Vol. 27, No. 10, pp.864-876, http:// dx.doi.org/10.1111/j.1559-1816.1997.tb00275.x.

Pacheco, C. (2004) Prácticas sexistas en el aula, UNICEF, Paraguay [online] http://www.unicef.org/paraguay/spanish/py_practicas_sexistas.pdf (accessed April 2019).

Paul, P. and Mukhopadhyay, K. (2010) 'Growth via intellectual property rights versus gendered inequity in emerging economies: an ethical dilemma for international business', Journal of Business Ethics, Vol. 91, No. 3, pp.359-378, Spinger Link, Switzerland.

Reverter, S. (2012) 'Introducción a la teoría feminista', in Estudios Feministas, de Género y Ciudadanía: Panorámica de la Investigación Aplicada, Universitat JaumeI. 
Reynolds, H.T. (1984) Analysis of Nominal Data. Sage University Paperon QASS, Thousand Oaks, Sage, California.

Roberge, G. and Durning, M. (2019) 'Gender gap in intellectual property rights: a case with European Union Trademars', 17th International Conference on Scientometrics and Informetrics, ISSI 2019 - Proceedings, Vol. 1, pp.944-951, Code 152215.

Rosser, S.V. (2003) 'Attracting and retaining women in science and engineering', Academe, Vol. 89, No. 4, p.24.

Rosser, S.V. (2009) 'The gender gap in patenting: Is technology transfer a feminist issue?', NWSA Journal, Vol. 21, pp.65-84.

Schwartz, F.N. and Zimmerman, J. (1992) Breaking with Tradition: Women and Work, the New Facts of Life, Warner Books, Inc., 1271 Avenue of the Americas, New York, NY 10020.

Wajcman, J. (2004) Techno Feminism, Polity Press, Cambridge.

Web Foundation (2017) Artificial Intelligence in Low and Middle-Income Countries, World Wide Web Foundation, Washington, DC [online] https://webfoundation.org/docs/2017/07 IAI_Report_WF.pdf (accessed April 2019).

Web Foundation (2018) Artificial Intelligence: Open Questions about Gender Inclusion, Policy Brief - W20 Argentina, World Wide Web Foundation, Washington, DC [online] http://webfoundation.org/ docs/2018/06/AI-Gender.pdf (accessed April 2019).

WIC (2018) AUTM Women Inventors Committee, Geneva, Switzerland.

WIPO (2019) PCT Yearly Review 2019: The International Patent System, WIPO, Geneva.

WIPO Statistics Database (2019) Last updated, June [online] https://www3.wipo.int /ipstats/keyindex.htm (accessed April 2019).

Writh, L. (2002) Romper el techo de cristal, las mujeres en puestos de dirección, Informes OIT, Ministerio de Trabajo y Asuntos Sociales, Madrid. 